\title{
ATUAÇÃO DA ENFERMEIRA NA INFECÇÃO POR TRICHOMONAS VAGINALIS
}

\author{
NURSE'S PERFORMANCE IN TRICHOMONAS VAGINALIS INFECTION
}

\author{
DESEMPEÑO DE LA ENFERMERA EN LA INFECCIÓN POR TRICHOMONAS VAGINALIS
}

\author{
Thiago José Matos ${ }^{1}$ \\ Júlia Karlla Campos Nascimento ${ }^{2}$ \\ Uirassú Tupinambá Silva de Lima ${ }^{3}$ \\ Alessandra do Nascimento Pontes ${ }^{4}$ \\ Thycia Maria Gama Cerqueira ${ }^{5}$ \\ Lara Malta Siqueira Barbosa ${ }^{6}$
}

RESUMO: INTRODUÇÃO: A tricomoníase é uma doença sexualmente transmissível (DST) negligenciada no Brasil. Essa doença é uma das DSTs mais prevalentes mundialmente. Esse estudo teve como objetivo analisar a atuação da enfermeira na infecção por Trichomonas vaginalis. METODOLOGIA: consistiu em um estudo de revisão integrativa de literatura, através de pesquisa nas bases de dados literatura latino-americana e do Caribe Ciências da Saúde (LILACS), Medical Literatura Análise e Retrieval System on-line (MEDLINE), Public Medline (Pu-bMed) e as bibliotecas virtuais Scientific Electronic Library Online (SciELO), essas escolhidas por sua larga difusão acadêmica. RESULTADOS E DISCUSSÃO: A busca foi realizada pelo acesso on-line e a amostra final desta revisão integrativa contém artigos dos anos de 2010 a 2016. Os artigos incluídos trataram do diagnóstico das principais infecções do trato geniturinário, a tricomoníase aparecendo como uma das três principais; da importância do conhecimento sobre essas patologias no que se

\footnotetext{
${ }^{1}$ Doutor em Inovação Terapêutica pelo Programa de Pós-graduação em Inovação Terapêutica (PPGIT/UFPE). Professor Assistente da Universidade Estadual de Ciências da Saúde de Alagoas na área de Parasitologia lotado no Núcleo de Ciências Biológicas (NUCIB/UNCISAL) e professor titular do Centro Universitário Cesmac. Docente Permanente do Programa de Pós-Graduação em Análise de Sistemas Ambientais (PPGASA/Cesmac) e do Mestrado Profissional em Ensino na Saúde e Tecnologia (MEST/Uncisal). Coordena o grupo de pesquisa Saúde, educação e meio ambiente. Conselheiro Regional pelo Conselho Regional de Farmácia de Alagoas.

${ }^{2}$ Graduanda em enfermagem pelo Centro Universitário Cesmac.

${ }^{3}$ Doutorando em Educação pela Faculdade de Humanidades e Artes da Universidad Nacional de Rosário - UNR. Psicólogo, graduado em Psicologia pelo Centro Universitário Cesmac. Enfermeiro, graduado em Enfermagem e Obstetrícia pela Universidade Federal de Alagoas. Mestre em Ensino na Saúde pela Faculdade de Medicina da Universidade Federal de Alagoas. Especialista em Gerontologia pela Universidade Estadual de Ciências da Saúde de Alagoas, em Metodologia do Ensino Superior pela UFAL e em Ensino de Enfermagem pela Escola Nacional de Saúde Pública da Fundação Instituto Osvaldo Cruz - FIOCRUZRJ. Neuropsicólogo pela Universidade Cândido Mendes -UCAMRJ. E-mail: uirassulima@yahoo.com.br.

${ }^{4}$ Doutoranda pela Universidade Mackenzie, Mestre em Modelagem Computacional, Membro do Núcleo de Robótica e Centro de Inovação e Tecnologia do CESMAC. Co-fundadora da Startup Mulheres Conectadas juntamente com Gesyca Santos com o propósito da transformação digital e equidade de gênero, conectando mulheres ao universo do Empreendedorismo, Tecnologia e Inovação é consultora de Tecnologia, Empreendedorismo e Startup credenciada pelo SEBRAE/AL e avaliadora de Projetos de Inovação pelo Instituto Federal do Espírito Santo. Atua nos processos de modelagem de solução, palestrante e Mentora. Membro Woman in Science é um Programa do British Council. Membro do Future Females Business School em parceria com o UK-Brazil Tech Hub! Líder de Comunidade da Sururu Valley. Atualmente é Embaixadora da Associação Brasileira de Startup de Saúde - ABSS.

${ }^{5}$ Graduada em Enfermagem pelo Centro Universitário Cesmac (2010); Doutoranda pelo programa de Doutoramento em Distúrbios do Desenvolvimento da Universidade Presbiteriana Mackenzie (2019); Mestra em Ciências da Saúde pela Universidade Federal de Alagoas (2013), Especialista em Saúde Pública (2012). Coordena o curso de Graduação em enfermagem do Centro Universitario Cesmac e a Especialização Saúde Pública com Ênfase em Saúde da Família. Possui sete anos de experiência profissional acadêmica como professora no ensino superior.

${ }^{6}$ Graduanda em enfermagem pelo Centro Universitário Cesmac.
} 
refere ao agente causal, sintomatologia, técnicas diagnósticas e tratamento correto para evitar complicações no curso crônico da infecção. CONSIDERAÇÕES FINAIS: Embora haja poucos trabalhos sobre a atuação dos enfermeiros frente a pacientes com tricomoníase, a presente revisão integrativa mostrou que os enfermeiros que atuam na área de saúde da mulher ou que receberem treinamento na área pode estar apto a diagnosticar e realizar os cuidados necessários para gerenciar/controlar as infecções do trato geniturinário, entre elas a tricomoníase, tanto em mulheres quanto em homens.

Palavras-chaves: DST. Trichomonas vaginalis. Saúde da mulher.

ABSTRACT: INTRODUCTION: Trichomoniasis is a neglected sexually transmitted disease (STD) in Brazil. This disease is one of the most prevalent STDs worldwide. This study aimed to analyze the role of nurses in Trichomonas vaginalis infection. METHODOLOGY: consisted of an integrative literature review study, through a search in the Latin American and Caribbean Literature Health Sciences (LILACS), Medical databases - bMed) and the Scientific Electronic Library Online (SciELO) virtual libraries, those chosen for their wide academic diffusion. RESULTS AND DISCUSSION: The search was performed through online access and the final sample of this integrative review contains articles from 2010 to 2016. The articles included dealt with the diagnosis of the main infections of the genitourinary tract, trichomoniasis appearing as one of the three main; the importance of knowledge about these pathologies with regard to the causal agent, symptomatology, diagnostic techniques and correct treatment to avoid complications in the chronic course of the infection. FINAL CONSIDERATIONS: Although there are few studies on the role of nurses in patients with trichomoniasis, this integrative review showed that nurses who work in the area of women's health or who receive training in the area may be able to diagnose and provide the necessary care to manage/control genitourinary tract infections, including trichomoniasis, in both women and men. evidenced that it is necessary that healthcare professionals, especially nurses, from all levels of care, have generic competences and skills related to this pathology, which include not only phenotypic knowledge and clinical aspects, but also the ability to quickly, effectively and safely guide their work processes. FINAL CON- SIDERATIONS: the nurse facing this clinical condition, needs to understand the unfolding network of signs and symptoms involved, so that then can align the Nursing Process (NP) for a more qualitative, autonomous, human and interprofessional assistance.

Keywords: DST. Trichomonas vaginalis. Women's health.

RESUMEN: INTRODUCCIÓN: La tricomoniasis es una enfermedad de transmisión sexual (ETS) desatendida en Brasil. Esta enfermedad es una de las ETS más prevalentes en todo el mundo. Este estudio tuvo como objetivo analizar el papel de las enfermeras en la infección por Trichomonas vaginalis. METODOLOGÍA: consistió en un estudio de revisión integradora de la literatura, a través de una búsqueda en la Literatura Latinoamericana y del Caribe en Ciencias de la Salud (LILACS), el Sistema de Análisis de Literatura Médica y Recuperación en Línea (MEDLINE), las bases de datos Public Medline $(\mathrm{Pu})$ - bMed) y la Electrónica Científica. Bibliotecas virtuales Library Online (SciELO), las elegidas por su amplia difusión académica. RESULTADOS Y DISCUSIÓN: La búsqueda se realizó a través del acceso online y la muestra final de esta revisión integradora contiene artículos de 2010 a 2016. Los artículos incluidos versaron sobre el diagnóstico de las principales infecciones del tracto genitourinario, apareciendo la tricomoniasis como una de las tres principales.; la importancia del conocimiento de estas patologías en cuanto al agente causal, los síntomas, las técnicas diagnósticas y el correcto tratamiento para evitar complicaciones en el curso crónico de la infección. CONSIDERACIONES FINALES: Si bien existen pocos estudios sobre el papel de las enfermeras en pacientes con tricomoniasis, esta revisión integradora mostró que las enfermeras que trabajan en el área de salud de la mujer o que reciben capacitación en el área pueden ser capaces de diagnosticar y brindar la atención necesaria. atención para manejar / controlar las infecciones del 
tracto genitourinario, incluida la tricomoniasis, tanto en mujeres como en hombres.

Descriptores: Tricomonas vaginalis. La salud de la mujer

\section{INTRODUÇÃO}

O objeto de pesquisa refere-se à atuação da enfermeira na infecção por Trichomonas vaginalis. A motivação pela realização dessa pesquisa se deu pelo fato das infecções pelo $T$. vaginalis geralmente estão associadas com outras doenças sexualmente transmissíveis (DSTs) e é um indicativo de comportamento sexual de risco, mas principalmente porque na maioria dos países, a tricomoníase não é monitorada e não existem programas de controle.

T. vaginalis é o agente etiológico da tricomoníase, uma DST muito comum causada pelo protozoário flagelado. Segundo a Organização Mundial de Saúde, em 2005, o total de casos novos de tricomoníase em adultos de 15 a 49 anos de idade foi de aproximadamente 248 milhões (OMS, 201I).

Os indivíduos infectados podem ser assintomáticos, oligossintomáticos ou sintomáticos, pois as manifestações clínicas dessa doença variam de irritação moderada à inflamação severa. De fato, cerca de 70\% dos infectados não apresentam sinais ou sintomas. No entanto, essa patologia tem sido relacionada ao maior risco de transmissão do vírus da imunodeficiência humana (HIV), ao nascimento prematuro e/ou ao baixo peso ao nascer, à predisposição das mulheres à infertilidade, ao desenvolvimento de doença pélvica inflamatória, ao câncer cervical, entre outros agravos (MACIEL et al, 2004).

O diagnóstico correto da tricomoníase é imprescindível, pois os mesmos sinais e sintomas podem ser causados pela infecção por outros patógenos. Nesse contexto, o Enfermeiro tem uma atuação importante, pois a coleta de material para colpocitologia pelo método de Papanicolau pode ser realizada por esse profissional. Esse exame não tem o objetivo de identificar as DSTs, mas pode auxiliar o reconhecimento do agente ou os efeitos citopáticos sugestivos da presença de algum agente causador de DST (Resolução COFEN № 38I/20II).

A tricomoníase não é uma doença de notificação compulsória e a ausência de estudos de base populacional para o cálculo de incidência dificulta a resolução dos problemas e a tomada de decisões, com o estabelecimento de intervenções, avaliação da efetividade e novos encaminhamentos (BRASIL, 2006).

Algumas políticas públicas explicitam a assistência pelo profissional de saúde à saúde sexual e reprodutiva, como PNAISM (Política Nacional de Atenção Integrada à Saúde da Mulher) e PNAISH (Política Nacional de Atenção Integral à Saúde do Homem). A PNAISM abrange os mais diversos dilemas que estão presentes na saúde da mulher, devendo atender a mulher em todo o seu ciclo de vida. Os princípios da política determinam a captação precoce das pacientes, permitir o acesso das usuárias aos três níveis de complexidade, o acolhimento amigável e um acompanhamento com a participação da usuária. Quanto à atenção as DST's, a PNAISM enfatiza que o SUS deverá consolidar a atenção básica para as mulheres e ampliar e qualificar a atenção clínico-ginecológica (BRASIL, 2007).

A prevenção e tratamento de DST's está contemplada em um dos objetivos específicos da PNAISH, que visa estimular a implantação e implementação da assistência em saúde sexual e reprodutiva, no âmbito da atenção integral à saúde. Caso a PNAISH já estivesse implantada em todo o território nacional, poderia minimizar a transmissão sexual do T. vaginalis (BRASIL, 2009). 
A PNAISH, instituída pela Portaria do Ministério da Saúde no 1.944 , de 27 de agosto de 2009, é uma política que prevê a facilitação e ampliação da população masculina aos serviços de saúde. Os princípios e diretrizes almejam atingir todos os níveis de atenção à saúde, sua implementação em todo o país com compatibilidade aos princípios do SUS e apoio à gestão e ao controle social, além de captar o homem para as intervenções da atenção primária e capacitação técnica de profissionais (BRASIL, 2009).

Um marco no Brasil foi à implantação da Rede Cegonha, que é uma estratégia do Ministério da Saúde que visando programar uma rede de cuidados para assegurar às mulheres o direito ao planejamento reprodutivo e a atenção humanizada à gravidez, ao parto e ao puerpério, bem como assegurar às crianças o direito ao nascimento seguro e ao crescimento $e$ desenvolvimento saudáveis (BRASIL, 2012).

Nesse sentido, o enfermeiro é um profissional que trabalha em saúde da mulher e assim pode atuar com educação em saúde para pessoas que não conhece essa doença. Assim, o objetivo desse estudo foi analisar as evidências científicas sobre a atuação do enfermeiro frente a pacientes infectados por $T$. vaginalis para redigir uma revisão integrativa da literatura sobre o tema. Neste sentido a pesquisa apresenta a seguinte pergunta norteadora: "quais as publicações existentes sobre a atuação do enfermeiro na infecção por Trichomonas vaginalis?

\section{METODOLOGIA}

Consistiu em um estudo de revisão integrativa de literatura. $\mathrm{Na}$ operacionalização dessa revisão, foram percorridas as seguintes etapas: delimitação da questão da pesquisa; estabelecimento de critérios de inclusão/exclusão para seleção dos estudos a serem analisados e apresentação da síntese da revisão.

Neste sentido a pesquisa teve a seguinte pergunta norteadora: "como se preconiza a atuação do enfermeiro na infecção por Trichomonas vaginalis a partir de evidências científicas atuais?

O levantamento bibliográfico foi realizado pela internet, por meio da Biblioteca Virtual de Saúde (BVS), nas bases de dados LILACS (Literatura Latino-Americana em Ciências da Saúde), SciELO (Scientific Eletronic Library Online).

Os critérios utilizados para seleção dos artigos foram: artigos que abordassem a temática em questão, redigidos na língua portuguesa e, publicados no período de janeiro de 2010 a dezembro de 2016 que apresentem o texto completo disponibilizado online. Para tal, utilizaram-se os seguintes descritores "DST", "Trichomonas vaginalis" e "Saúde da mulher".

Os critérios de exclusão foram: artigos que não abordassem parasitoses intestinais, fora da temática em questão, publicados fora do período estabelecido e não estavam disponibilizados online.

A busca foi realizada pelo acesso on-line e a amostra final desta revisão integrativa foi constituída de 17 artigos. Após a análise dos textos na integra, foi realizada uma síntese dos dados, contemplando autores, ano de publicação, objetivos, resultados e conclusões. A apresentação dos dados foi realizada de forma descritiva, procedendo-se a categorização dos dados extraídos dos estudos selecionados.

\section{RESULTADOS E DISCUSSÃO}

\section{I Marco teórico da revisão}

Este referencial teórico visa resgatar algumas teorias e conceitos que frequentemente 
fornecem base para os estudos de dados primários secundários acerca da tricomoníase nas ciências da saúde.

O T. vaginalis recebeu diferentes denominações: T. vaginale, T. vaginae, T. irregulares ou T. vulvo-vaginales. Esse parasito foi descrito e classificado por Alfred Donné em i836, após ter sido isolado de uma mulher com vaginite. Ehremberg reforçou sua classificação como $T$. vaginalis. Hoehne em 1916 apresentou a relação entre o corrimento vaginal e o parasita (SIQUEIRA et al., 2008).

Esse protozoário é um flagelado extracelular que habita o trato genital humano. Durante seu ciclo evolutivo, se apresenta somente sob a forma trofozoítica. As condições físico-químicas do meio em que o parasito se encontra, por exemplo, $\mathrm{pH}$, temperatura, tensão de oxigênio e força iônica, podem resultar em variações em sua forma (DE CARLI et al., 2005).

O T. vaginalis é um protozoário anaeróbio facultativo, crescendo em condições hostis como na ausência de oxigênio, em pH na faixa de 5 a 7,5 e temperaturas entre $20^{\circ} \mathrm{C}$ e $40^{\circ} \mathrm{C}$. Utiliza como fonte de energia glicose, maltose, amido e galactose e possui a capacidade de manter o glicogênio em reserva como fonte de energia. $O$ único hospedeiro conhecido do $T$. vaginalis é o ser humano (MUNDODI et al., 2004).

A tricomoníase é uma doença venérea e o risco de infecção por ato sexual é de 6o a $80 \%$. O T. vaginalis é resistente por mais de uma semana sobre o prepúcio de um homem que se contaminou após relação sexual com uma mulher infectada, por algumas horas na urina ou no sêmen ejaculado. O homem é considerado o vetor do parasito, pois através da ejaculação os protozoários presentes na mucosa da uretra são encaminhados à vagina pelo esperma. A transmissão não sexual é rara e a tricomoníase neonatal em mulheres é adquirida durante o parto (FICHOROVA et al., 2012).

Em recém-nascidos $(\mathrm{RN})$ a infecção pode ocorrer durante a passagem pelo canal de parto, pois o epitélio escamoso da vagina da $\mathrm{RN}$ é suscetível à ação de estrógenos maternos e permite a colonização (DE CARLI et al., 2005). O recém-nascido pode ser infectado através de transmissão vertical no momento do parto ou através da rotura das membranas fetais, mas a alcalinização do $\mathrm{pH}$ vaginal em 6 semanas erradica naturalmente o parasita, portanto a descoberta de T. vaginalis em crianças pode ser indício de abuso sexual (BELLANGER et al., 2008).

A tricomoníase é responsável por mais da metade das DSTs não virais (FICHOROVA et al., 2012). Sua incidência depende de vários fatores como estilo de vida, número de parceiros sexuais, higiene pessoal, idade, fase do ciclo menstrual, presença de outras DSTs, nível socioeconômico e educacional baixo (DE CARLI et al., 2005), sendo alta em indivíduos de nível socioeconômico baixo tanto em países desenvolvidos como em desenvolvimento, em pacientes de clínicas ginecológicas, pré-natais e serviços de DSTs (GOODMAN et al., 2oII).

As parceiras de homens infectados apresentam o protozoário em $80 \%$ a $100 \%$ dos casos (BARROS, 2009). É estimado que 746 novos casos de HIV por ano sejam atribuídos aos processos facilitadores da tricomoníase (FICHOROVA et al., 2012).

As infecções pelo $T$. vaginalis geralmente estão associadas com outras DSTs e é um indicativo de comportamento sexual de risco. Na maioria dos países, a tricomoníase não é monitorada e não existem programas de controle. A infecção caso não seja tratada pode persistir por até 5 anos (LEON et al., 2009).

O período de incubação do parasito varia entre 4 a 8 dias e a infecção não se restringe à 
vagina, podendo alcançar a cérvice, a uretra, as glândulas parauretrais e a bexiga (BARROS, 2009). Nas mulheres $T$. vaginalis invade a genitália interna induzindo o desenvolvimento de vaginite (MONTENEGRO; REZENDE, 2008). O protozoário flagelado realiza o parasitismo com sucesso em um ambiente desfavorável através de seus mecanismos de patogenicidade e por sua capacidade de se esquivar da resposta imune do hospedeiro.

A infecção por T. vaginalis ocasiona uma resposta imune agressiva com inflamação do epitélio vaginal e exocérvice. Essa inflamação é caracterizada por um infiltrado de leucócitos, entre os quais estão as células-alvo do vírus da imunodeficiência humana, os linfócitos $\mathrm{T}$ $\mathrm{CD}_{4+}$ e os macrófagos, nos quais o HIV pode se ligar e obter acesso. Além do mais o protozoário pode ocasionar pontos hemorrágicos na mucosa, facilitando o acesso do vírus à corrente sanguínea, facilitando a entrada do vírus, gerando uma probabilidade 8 vezes maior de se contrair o HIV comparado aos indivíduos não infectados. O protozoário tem aptidão de degradar o inibidor de protease leucocitária secretória, um fator conhecido por impedir o ataque do vírus às células. Deste modo, o diagnóstico e tratamento adequado do T. vaginalis implica em uma redução de transmissão do HIV (DE CARLI et al., 2005). A tricomoníase expande a porta de saída para HIV- positivos e a porta de entrada para HIV-negativos (MUNDODI et al., 2004).

A infecção é acompanhada também de prurido, irritações vaginais, dor no baixo ventre, dor durante o ato sexual ou dificuldade para executá-lo (dispareunia de introito), disúria, poliúria. A cérvix além de eritematosa pode apresentar petéquias e sangrar ao contato. A vagina pode apresentar-se edemaciada e eritematosa, com erosão e pontos hemorrágicos, colpite difusa ou focal com aspecto de morango (DE CARLI et al., 2005).

No homem a doença é comumente assintomática ou pode ser observada como uma uretrite com secreção leitosa ou purulenta e prurido leve na uretra. Durante a manhã, antes da primeira urina, pode ser observado um corrimento claro, viscoso e em pouca quantidade, com desconforto ao urinar e hiperemia do meato uretral. Durante o restante do dia a secreção é escassa. O parasito desenvolve-se melhor no trato genital masculino, pois há uma reserva de glicogênio favorável, sendo que este ainda pode alocar-se na bexiga e na vesícula seminal (SIQUEIRA al., 2008).

O diagnóstico clínico raramente será realizado através da sintomatologia, sendo a investigação laboratorial o modo mais confiável e extremamente essencial à identificação do parasita e para a diferenciação da tricomoníase em relação a outras DSTs (DE CARLI et al., 2005). A investigação laboratorial orienta o tratamento adequado e auxilia no controle da infecção (DE CARLI et al., 2005).

O metronidazol é um antibiótico da classe nitromidazole e é considerado o tratamento de primeira linha para infecção por $T$. vaginalis (FICHOROVA et al., 20I2). Esse medicamento, administrado por via oral a ambos os parceiros, leva à cura da infecção (TORTORA, G.J., 2005). A dose de administração é de aproximadamente $2 \mathrm{~g}$, em dose única, e tem eficácia de 80 a $88 \%$. O tratamento sempre deve ser administrado simultaneamente ao parceiro sexual. Nesses casos, o índice de cura pode ser superior a 95\% (SIQUEIRA et al., 2008). O metronidazol é um fármaco não tricomonicida, ele é ativado nos hidrogenossomas de T. vaginalis, ocasionando uma redução anaeróbica do seu grupo nitro, produzindo fatores citotóxicos em seu radical nitro-lítio. Esta etapa não produz resultados em patógenos resistentes (JAIN et al., 20II).

Não há vacina contra o $T$. vaginalis, então é recomendado que se evitasse a multiplicidade de parceiros, que se faça uso de preservativo de látex, o diagnóstico e o 
tratamento precoce em serviços de saúde, e se evite a automedicação (SIQUEIRA et al., 2008). A circuncisão não altera a incidência de DST's na população, sendo que um controle e gestão das infecções sexualmente transmissíveis, assim como o tratamento concomitante de parceiros, os devidos aconselhamentos e reduzir riscos são as melhores alternativas para diminuir e evitar novos incidentes (MEHTA et al., 2009). Entretanto, segundo Tobian; Gray; Quin (2010), a circuncisão de neonatos é vista como ferramenta de prevenção de aquisição do vírus da imunodeficiência adquirida e papiloma vírus humano. Em parceiras de homens circuncidados, a incidência de vaginose bacteriana e $T$. vaginalis foi reduzida $40 \%$ e $48 \%$ respectivamente.

Portanto, apesar da tricomoníase ser muito comum globalmente, ela não é considerada uma prioridade em saúde (SCHWEBKE; BURGESS, 2004). Avaliar a incidência de mulheres infectadas é necessário para que haja o estabelecimento de programas de controle da doença para prevenção e tratamento da população e melhora da saúde reprodutiva (LEON et al., 2009).

\subsection{Estado da arte dos artigos publicados}

Este estado da arte teve como propósito saber o que está sendo publicado sobre a tricomoníase no recorte temporal previsto no plano metodológico dessa revisão.

A tabela I mostra os artigos científicos organizados em ordem cronológica para permitir a observação da evolução histórica referente ao tema (POMPEO; ROSSI; GALVÃO, 2008). Os artigos incluídos nessa RI trataram do diagnóstico das principais infecções do trato geniturinário, a tricomoníase sempre aparecendo como uma das três principais; da importância do conhecimento sobre essas patologias no que se refere ao agente causal, sintomatologia, técnicas diagnósticas e tratamento correto para evitar complicações em longo prazo, no curso crônico da infecção; de como as condições sociais e demográficas influenciam sobre o surgimento e manutenção dessas patologias; e principalmente da necessidade dos enfermeiros da atenção primária deterem todo esse conhecimento e desenvolverem as competências para o acompanhamento e gerenciamento dessas patologias, entre elas a tricomoníase, na população acompanhada pelos mesmos.

A maioria dos trabalhos define a vaginite como uma condição inflamatória da vagina, que pode resultar em sintomas como leucorreia, prurido, dor, irritação, entre outros. Infecções por diferentes patógenos podem resultar em vaginites, entre ele o $T$. vaginalis. Pode ocorrer em um episódio único ou recorrente ao longo da vida da mulher. Algumas mulheres se dirigem aos serviços médicos, mas a maioria realiza automedicação de forma inapropriada, conforme relata Mashburn (2006).

Com relação ao diagnóstico da tricomoníase, Allen-Davis et al. (1998; 2002) avaliaram a concordância entre o diagnóstico por telefone realizado por enfermeiro e o atendimento médico de pacientes com vulvovaginite. Nesses trabalhos ficou nítida a necessidade de educação permanente das enfermeiras para o alcance do objetivo do programa e que a triagem telefônica não é adequada para diagnosticar e tratar vulvovaginites.

Lowe e Ryan-Wenger (2003) avaliaram a prevalência de vaginite e infecções do trato urinário em militares do sexo feminino durante o posicionamento estratégico de tropas do exército e da marinha e a acurácia do autodiagnostico nesse grupo, devido à zona de combate ser uma área que contribui para o desenvolvimento do parasito, além da assistência à saúde primária ser ineficiente nestas áreas. Nenhum dos algoritmos alcançou o objetivo de $95 \%$ de acurácia, evidenciando a necessidade de melhorar esses instrumentos para esse tipo de população, em que há vários fatores de risco, comportamentais e situacionais, predispondo as 
mulheres às infecções do trato geniturinário (RYANWENGER et al., 20ıo).

Um artigo comparou três métodos diagnósticos para infecção pelo $T$. vaginalis: aglutinação pelo látex, esfregaço em salina e cultura e concluiu que o teste de aglutinação em látex é um teste altamente sensível para se detectar a infecção por $T$. vaginalis, além de ser rápido, podendo vir a ser utilizado para análises e definições de diagnóstico (ADUSARKODIE et al., 2004).

Rassjo e colaboradores estimaram a prevalência de DSTs tratáveis em adolescentes em uma clínica de saúde, avaliaram o uso do algoritmo para manejo da síndrome do corrimento vaginal anormal recomendado pelas diretrizes nacionais de Uganda e compararam-no a outros fluxogramas teóricos. Eles observaram uma que a prevalência de infecção por $T$. vaginalis foi $8,0 \%$, em meninas e o\% em meninos, e que o melhor algoritmo, com maior sensibilidade, especificidade e valor preditivo positivo, para o manejo das DSTs nessa população utilizava fatores comportamentais e demográficos da mesma.

A prevalência de DSTs tratáveis foi estimada em adolescentes em uma clínica de saúde. Mensch et al. (2008) investigaram o sexo antes do casamento em uma área rural de Malawi. A prevalência de DST entre mulheres profissionais do sexo, de município de médio porte do interior paulista foi avaliada por Baldin-Dal Pogetto; Silva; Parada (20iI) demonstrando uma alta prevalência de DST em profissionais do sexo. As relações entre a desorganização social dos bairros e apresentação de tricomoníase foi avaliada entre adultos jovens dos EUA por Ford e Browning (20II), revelando que as condições sociais da população e de infraestrutura dos bairros estão associadas com a aquisição de DSTs e que mais pesquisas são necessárias para explorar os mecanismos pelos quais essas condições influenciam a aquisição de DSTs.

O estudo de Lopes et al. (2008), que avaliou as características da população feminina notificada por DST durante um período de sete anos em Araraquara revelou que a maioria das mulheres foi acometida por HPV/condiloma, seguido por tricomoníase; tinham entre I939 anos, donas de casa, com parceiro fixo, heterossexuais, se relacionaram apenas com um parceiro no período de um no e não faziam uso do preservativo. Esses dados revelam como o conhecimento das características que predispõem as mulheres às DSTs é fundamental para a enfermagem que atua em atenção primária, para permitir que estratégias específicas sejam adotadas visando diminuir os casos de DSTs entre a população feminina.

Marion (2009) mostrou em seu trabalho a importância de um programa sério, de longo período e intensivo na diminuição de novos casos de DSTs, entre elas, de tricomoníase, ao comparar a eficácia do Well Woman Program (WWP) - um programa de intervenção intensiva realizado por enfermeiros - com um programa de intervenção mínima, revelando que a assistência de modo intensivo por enfermeiros qualificados contribui para a redução do risco de aquisição de DST's.

Vários trabalhos relacionaram a ocorrência de DSTs com outras patologias. Falsetti et al. (2003) descreveram e compararam adolescentes do sexo feminino com ou sem diabetes em relação ao uso de preservativos, número de gestações e aquisição de DSTs, evidenciando que não há correlação entre diabetes e tricomoníase. Wiley et al. (2012) descreveram o risco para infecção por HPV6/II/16/18 em mulheres jovens sexualmente ativas e Souza et al. (2013) determinaram a prevalência de sete patógenos clinicamente importantes causadores de DSTs (C. trachomatis, N. gonorrhoeae, M. genitalium, T. vaginalis, herpes simplex virus I [HSV-I], HSV-2 and T. pallidum) em indivíduos infectados ou não por HIV.

Cinco artigos descreviam uma revisão da literatura. O papel dos enfermeiros está em 
constante modificação já que estão sempre se deparando com casos que vão de menor injúria a de maior complexidade. Os agentes etiológicos, diagnóstico e cuidado das três infecções vaginais mais comuns, vaginose bacteriana, tricomoníase e candidíase foram revisados por Mashburn (2006), já que é frequentemente diagnosticadas de forma errônea, o que pode levar ao tratamento incorreto e em longo prazo a problemas de saúde mais severos.

Lewin (2007), considerando que os enfermeiros pediátricos podem ser requisitados para conduzir uma pesquisa de abuso sexual em crianças, escreveu uma revisão considerando os patógenos que requerem cultivo para o diagnóstico, período de incubação, sintomatologia, posicionamento adequado da criança para a obtenção de amostras se necessário. Entre os agentes revisados constava o $T$. vaginalis.

Holloway (2010) descreve a importância dos enfermeiros terem o background de informação necessário para ficarem mais confiantes para lidarem com as questões de saúde da mulher, como por exemplo, conhecer as causas, sinais, sintomas, e os tratamentos disponíveis para as vaginites. Na mesma linha, Summers (20II) afirma que se os enfermeiros realizarão o diagnóstico e conduzirão o tratamento, é imprescindível o conhecimento da tricomoníase. Por fim, Mashburn realizou uma atualização do tema em 2006.

\begin{tabular}{|c|c|c|c|}
\hline $\begin{array}{c}\text { IDENTIFICAÇÃO DO } \\
\text { ESTUDO }\end{array}$ & OBJETIVOS & $\begin{array}{l}\text { CARACTERÍSTICAS } \\
\text { METODOLÓGICAS }\end{array}$ & RESULTADOS \\
\hline $\begin{array}{l}\text { Prevalence of sexually } \\
\text { transmitted infections among } \\
\text { adolescents in Kampala, } \\
\text { Uganda, and theoretical models } \\
\text { for improving syndromic } \\
\text { management (RASSJO et al., } \\
2006 \text { ) }\end{array}$ & $\begin{array}{l}\text { Estimar a prevalência de } \\
\text { DSTs tratáveis em } \\
\text { adolescentes em uma clínica } \\
\text { de saúde, avaliar o uso do } \\
\text { algoritmo para manejo da } \\
\text { síndrome do corrimento } \\
\text { vaginal anormal recomendado } \\
\text { pelas diretrizes nacionais de } \\
\text { Uganda. }\end{array}$ & $\begin{array}{l}\text { Adolescentes com vida sexual } \\
\text { ativa que foram à clínica em } \\
\text { Kampala, Uganda foram } \\
\text { examinadas e entrevistas. } \\
\text { Amostras foram coletadas e } \\
\text { testadas para infecção por } \\
\text { Chlamydia trachomatis, Neisseria } \\
\text { gonorrhoea, e Trichomonas } \\
\text { vaginalis por reação de } \\
\text { polimerização em cadeia (PCR); } \\
\mathrm{N}=199 \text { do sexo feminino; } \\
\mathrm{N}=\text { Io7 do sexo masculino. }\end{array}$ & $\begin{array}{l}\text { Prevalência de TV foi } 8.0 \% \text {, em } \\
\text { meninas e o\% em meninos. }\end{array}$ \\
\hline $\begin{array}{l}\text { Etiology, diagnosis, and } \\
\text { management of vaginitis } \\
\text { (Mashburn, 2006). }\end{array}$ & $\begin{array}{l}\text { Descrever os três tipos de } \\
\text { infecções vaginais mais } \\
\text { comuns: vaginose bacteriana, } \\
\text { tricomoníase e candidíase. } \\
\text { Técnicas apropriadas de } \\
\text { diagnostic e terapias são } \\
\text { revisadas. }\end{array}$ & Revisão bibliográfica. & - \\
\hline $\begin{array}{l}\text { Sexually transmitted infections } \\
\text { in preadolescent children. } \\
\text { (LEWIN, 2007) }\end{array}$ & $\begin{array}{l}\text { Enfermeiros pediátricos } \\
\text { podem ser requisitados para } \\
\text { conduzir uma pesquisa de } \\
\text { abuso sexual em crianças. }\end{array}$ & Revisão bibliográfica & $\begin{array}{l}\text { A criança ou adolescente que } \\
\text { possui alguma DST impacta } \\
\text { tanto o emocional da mesma } \\
\text { quanto o da família. }\end{array}$ \\
\hline $\begin{array}{l}\text { A prospective study of genital } \\
\text { infections in Hamedan, Iran. } \\
\text { (SHOBEIRI; NAZARI, 2006). }\end{array}$ & $\begin{array}{l}\text { Realizar um estudo } \\
\text { prospectivo sobre infecções do } \\
\text { trato geniturinário feminino }\end{array}$ & $\begin{array}{l}\text { Estudo prospectivo; } \\
\text { N=540 mulheres; entrevista } \\
\text { sobre a ocorrência de qualquer } \\
\text { secreção vaginal ou uretral; } \\
\text { coletar de dois swabs vaginais. }\end{array}$ & $\begin{array}{l}\text { Prevalência de candidíase, } \\
\text { tricomoníase, e vaginose } \\
\text { bacteriana foi I7.2, I8.I, e 28.5\%, } \\
\text { respectivamente; } \\
\text { Swab da cervix uterina é } \\
\text { melhor para o diagnóstico da } \\
\text { infecção por Trichomonas } \\
\text { vaginalis. }\end{array}$ \\
\hline $\begin{array}{l}\text { Opportunities for treating } \\
\text { sexually transmitted infections } \\
\text { and reducing HIV risk in rural } \\
\text { South Africa. (FROHLICH et } \\
\text { al., 2007). }\end{array}$ & $\begin{array}{l}\text { Determinar a distribuição } \\
\text { etiológica de DSTs e a } \\
\text { prevalência de infecção pelo } \\
\text { HIV nos participantes. }\end{array}$ & $\begin{array}{l}\text { Estudo de corte transversal } \\
\text { conduzido em uma comunidade } \\
\text { rural da África do Sul entre } \\
\text { setembro e novembro de 2002; } \\
\mathrm{N}=277 \text {; } \\
\text { Coleta de swabs vulvovaginais } \\
\text { para pesquisa de: Neisseriae } \\
\text { gonorrheae, Chlamydia trachomatis } \\
\text { e Trichomonas vaginalis - PCR } \\
\text { Teste sorológico foi realizado } \\
\text { para sífilis e infecção pelo HIV. }\end{array}$ & $\begin{array}{l}\text { Prevalência da infecção pelo } \\
\text { HIV: } 43,7 \% \text {; } \\
\text { 50\% tinham uma DST; } \\
\text { Todas as infecções eram } \\
\text { assintomáticas. }\end{array}$ \\
\hline
\end{tabular}


Características da população feminina notificada por DSTs no município de Araraquara. (LOPES et al., 2008)
Caracterizar a população feminina notificada por DST em Araraquara entre $2000 \mathrm{e}$ 2006 quanto à etiologia, faixa preservativo.

\section{Sexual Behavior and STI/HIV Status Among Adolescents in Rural Malawi: An Evaluation of the Effect of Interview Mode on Reporting. (MENSCH et al., 2008).} diagnóstico clínico de vaginose bacteriana, candidíase, e tricomoníase, comparando um protocolo tradicional padronizado com al., 2009).

Validity of the symptomatic
approach used by nurses in
diagnosing vaginal infections.
(KISA; TASKIN, 2009).
The Well Woman Program: a
community-based randomized
trial to prevent sexually
transmitted infections in low-
income African American
women.
(MARION et al., 2009)
Accuracy of vaginal symptom
selfdiagnosis algorithms for
deployed military women.
(RYAN WENGER et al., 20I0).

Nursing considerations in patients with vaginitis. (HOLLOWAY, 2010).

\begin{tabular}{cc}
$\begin{array}{c}\text { Identifying non-viral } \\
\text { gynaecological conditions. } \\
\text { (SUMMERS, 20II) }\end{array}$ & $\begin{array}{c}\text { miscutir as três infecções } \\
\text { ginecológicas mais comuns } \\
\text { com as quais as mulheres se } \\
\text { apresentam nas emergências: } \\
\text { candidíase, vaginose }\end{array}$ \\
$\begin{array}{c}\text { Neighborhood social } \\
\text { disorganization and the }\end{array}$ & $\begin{array}{c}\text { Examinar as relações entre } \\
\text { desteriana, tricomoníase }\end{array}$ \\
$\begin{array}{c}\text { acquisition of trichomoniasis } \\
\text { among young adults in the }\end{array}$ & vizinhança e tricomoníase \\
\hline
\end{tabular}
etária, ocupação, parceiro fixo ou não, práticas sexuais, número de parceiros no ano, uso e frequência do uso de

Investigar o sexo antes do casamento em uma área rural de Malawi

\section{Estimar a acurácia do} uma técnica molecular.

Análise documental de tabelas construídas a partir das fichas de notificação de DST

\section{Entrevista com mulheres} solteiras de $15^{-21}$ anos, realizada por computador ou pessoalmente.

Coleta de amostras para infecção por HIV e gonorreia, Chlamydia, e tricomoníase; Entrevista realizada por enfermeiro

Estudo prospectivo comparativo clinico;

$\mathrm{N}=535$ militares do sexo feminino com queixas vulvovaginais

$\mathrm{N}=300$ mulheres casadas;

Examinar a validade e efetividade de diagnóstico de infecções do trato geniturinário baseado nos sintomas, realizado por enfermeiros da área de saúde da mulher.

Comparar a eficácia do Well Woman Program (WWP) um programa de intervenção intensiva realizado por enfermeiros - com um programa de intervenção mínima

Avaliar a acurácia do auto diagnóstico de infecções do trato geniturinário em militares do sexo feminino

Explorar as causas, sinais, sintomas, e tratamentos para das vaginites para prover enfermeiros com o

background de informação necessário para ficarem mais confiantes para lidarem com as questões de saúde da mulher. 2006;

Aplicação questionário; 3 diagnósticos para cad participante: I) enfermeiro; 2) clínico feito por médico; e 3) diagnóstico microscópico feito pelo médico após coleta de amostras.

Estudo randomizado e controlado baseado na comunidade;

Mulheres afro-americanas com história de DSTs e residentes em área de risco.

\section{$\mathrm{N}=546$ militares do sexo} feminino

Coleta de swab; uso do cartão FemExam para medição do $\mathrm{pH}$ e o guia de tomada de decisão. Entre o diagnóstico potencial estava a tricomoníase.
825 notificações; a maioria das mulheres foi acometida por $\mathrm{HPV} /$ condiloma, seguido por tricomoníase; tinham entre 19 39 anos, donas de casa, com parceiro fixo, heterossexuais, se relacionaram apenas com um parceiro no período de um ano e não faziam uso do preservativo.

Em Malawi e Kenya, o modo de entrevistar e as questões afetaram a reportagem da atividade sexual.

\section{Sintomas:}

Leucorreia, prurido/irritação, mau cheiro, queimação, dor, desconforto;

8 casos (I. $5 \%$ ) de tricomoníase; Sensibilidade do teste - 99,6\% para tricomoníase quando comparado com o molecular.

Maior sensibilidade para diagnosticar candidíase que vaginose bacteriana $e$ tricomoníase.
No $15^{\circ}$ mês as mulheres que participavam do WWP tinham $20 \%$ menos probabilidade de apresentarem DST que as que participavam do programa de intervenção mínima.

A acurácia do auto diagnóstico foi $56 \%$ para tricomoníase.

A taxa de falso-positivos foi 20.3\% para tricomoníase.

A taxa de falso-negativos foi 23.7\% tricomoníase
Revisão bibliográfica

Diagnóstico de tricomoníase amostra de urina;

Dados organização vizinhança

derivados do 2000 US Census -
Tricomoníase foi mais frequente em bairros com elevada concentração de negros, e maior concentração de 


\begin{tabular}{|c|c|c|c|}
\hline $\begin{array}{l}\text { United States. (FORD; } \\
\text { BROWNING, 20II). }\end{array}$ & & $\begin{array}{c}\text { composição étnica e racial, } \\
\text { concentração da pobreza, e } \\
\text { instabilidade residencial } \\
\mathrm{N}=\text { II } 370 \text { indivíduos de } 4912 \\
\text { bairros }\end{array}$ & pobreza. \\
\hline $\begin{array}{l}\text { Prevalência de doenças } \\
\text { sexualmente transmissíveis em } \\
\text { mulheres profissionais do sexo, } \\
\text { em um município do interior } \\
\text { paulista, Brasil. (BALDIN-DAL } \\
\text { POGETTO et al., 2oII) }\end{array}$ & $\begin{array}{l}\text { Identificar a prevalência de } \\
\text { DST entre mulheres } \\
\text { profissionais do sexo, de } \\
\text { município de médio porte do } \\
\text { interior paulista. }\end{array}$ & $\begin{array}{c}\text { Este estudo de prevalência } \\
\text { populacional foi realizado no } \\
\text { ano } 2008 \text { com } 102 \text { profissionais } \\
\text { do sexo. }\end{array}$ & $\begin{array}{c}\text { A prevalência geral de DST foi } \\
\text { 71,6\%. } \\
\text { A prevalência de tricomoníase } \\
\text { foi de } 3,0 \% \text {. }\end{array}$ \\
\hline $\begin{array}{c}\text { Behavioral and } \\
\text { sociodemographic risk factors } \\
\text { for serological and DNA } \\
\text { evidence of HPV6, II, 16, 18 } \\
\text { infections. (WILEY et al., 2012). }\end{array}$ & $\begin{array}{c}\text { Descrever o risco para } \\
\text { infecção por HPV6/II/ı6/ı8 } \\
\text { em mulheres jovens } \\
\text { sexualmente ativa }\end{array}$ & $\begin{array}{c}\mathrm{N}=2409 \\
\text { Idade }-\mathrm{I} 6-23 \text { anos. } \\
\text { Foi avaliado histórico de outras } \\
\text { DST, entre elas tricomoníase. }\end{array}$ & $\begin{array}{l}\text { Somente o número de parceiros } \\
\text { sexuais, infecção por } \\
\text { Chlamydia e/ou Trichomonas } \\
\text { vaginalis estavam relacionadas } \\
\text { positivamente com a infecção } \\
\text { por HPV6/II- e 16/I8-DNA; e } \\
\text { HPV6/II-DNA } \\
\text { respectivamente. }\end{array}$ \\
\hline $\begin{array}{l}\text { Vaginal infections update. } \\
\text { (MASHBURN, 2012). }\end{array}$ & $\begin{array}{l}\text { Descrever a etiologia, fatores } \\
\text { de risco, sintomas, } \\
\text { diagnósticos e tratamentos } \\
\text { das três infecções do trato } \\
\text { geniturinários mais comuns: } \\
\text { vaginose bacteriana, } \\
\text { tricomoníase e candidíase. }\end{array}$ & Revisão bibliográfica & -...- \\
\hline $\begin{array}{c}\text { Simultaneous Detection of } \\
\text { Seven Sexually Transmitted } \\
\text { Agents in Human } \\
\text { Immunodeficiency Virus- } \\
\text { Infected Brazilian Women by } \\
\text { Multiplex Polymerase Chain } \\
\text { Reaction. (SOUZA et al., 2013). }\end{array}$ & $\begin{array}{c}\text { Determinar a prevalência de } 7 \\
\text { patógenos clinicamente } \\
\text { importantes causadores de } \\
\text { DSTs (Chlamydia trachomatis, } \\
\text { Neisseria gonorrhoeae, } \\
\text { Mycoplasma genitalium, } \\
\text { Trichomonas vaginalis, herpes } \\
\text { simplex virus I [HSV-I], } \\
\text { HSV-2, and Treponema } \\
\text { pallidum) }\end{array}$ & $\begin{array}{c}\text { PCR } \\
\text { Mulheres brasileiras infectadas } \\
\text { ou não por HIV }\end{array}$ & $\begin{array}{l}\text { Foi possível identificar todas as } \\
\text { DSTs por PCR e as associações } \\
\text { entre DSTs e infecção por } \\
\text { HIV. }\end{array}$ \\
\hline $\begin{array}{l}\text { The role of nursing in the } \\
\text { prevention and control of } \\
\text { trichomoniasis in women. } \\
\text { (Costa, et al., 2021) }\end{array}$ & $\begin{array}{l}\text { Revisar a literatura sobre a } \\
\text { atuação do enfermeiro no } \\
\text { diagnóstico, tratamento, } \\
\text { prevenção e conscientização } \\
\text { sobre os riscos da } \\
\text { tricomoníase em mulheres. } \\
\text { Material e métodos: Esse } \\
\text { estudo foi realizado com } \\
\text { busca eletrônica em base de } \\
\text { dados como: PubMed, SciElo, } \\
\text { LILACS e livros para } \\
\text { ampliação sobre o tema. }\end{array}$ & Revisão bibliográfica & $\begin{array}{l}\text { Os artigos revisados, poucos } \\
\text { abordam especificamente sobre } \\
\text { o papel da enfermagem frente a } \\
\text { essa parasitose, a maioria } \\
\text { abordava sobre diagnóstico } \\
\text { médico por meio da coleta de } \\
\text { material para avaliação } \\
\text { microscópica da secreção } \\
\text { vaginal, da antibióticoterapia, } \\
\text { da sintomatologia e da } \\
\text { prevenção com uso de } \\
\text { preservativo. }\end{array}$ \\
\hline
\end{tabular}

Fonte: Dados da pesquisa, 202I.

\section{CONSIDERAÇÕES FINAIS}

Essa revisão integrativa mostrou que as enfermeiras que atuam em saúde da mulher ou que vierem a realizar treinamento na área podem estar aptos a diagnosticar e a prescrever os necessários os cuidados necessários para gerenciar e controlar as infecções do trato geniturinário, entre elas a tricomoníase, tanto em adultos, mulheres principalmente, quanto em crianças e pré-adolescentes.

A leitura dos artigos revela ser necessário uma ampliação dos métodos para diagnosticar tricomoníase, assim como, a carência de mais políticas públicas que sejam eficientes para interferir no curso da mesma, bem como esquemas de rastreio e notificação. 
Conclui-se que há a necessidade de que as enfermeiros sejam mais engajadas no desenvolvimento de pesquisas sobre o tema. Além do mais, o conhecimento dos fatores sociais e demográficos da população é de fundamental importância, pois influencia na prevalência das DSTs na população, sendo essa percepção necessária também as enfermeiras, pois poderá impactar em suas ações para com a população.

A implantação de unidades primárias de saúde em áreas carentes e rurais coopera para a educação em saúde, para o monitoramento e acompanhamentos dos pacientes sujeitos a tricomoníase, aumentando a disponibilidade do exame Papanicolau, interferindo no ciclo do parasito e aumentado a cobertura de usuárias beneficiadas. Mesmo com a Estratégia Saúde da Família, a adesão de usuárias em fase sexual ativa é baixa, fato que pode ser explicado devido aos mitos relacionados à monogamia e baixo conhecimento sobre a tricomoníase. $O$ tratamento da parasitose deve ser acompanhado sistematicamente pela enfermeira pela equipe de saúde, que deve atentar-se aos fatores carcinogênicos que podem ser instalados devido ao uso do fármaco metronidazol, bem como o surgimento de cepas resistentes.

\section{REFERENNCIAS}

ALLEN-DAVIS, J. T. et al. Assessment of vulvovaginal complaints: agreement between phone and office management. Prim Care Update Ob Gyns. v. 5, n. 4, 1998.

ALLEN-DAVIS, J. T. et al. Assessment of Vulvovaginal Complaints: Accuracy of Telephone Triage and In-Office Diagnosis. Obstetrics \& Gynecology, v. 99, n. I, 2002.

BALDiN-DAL POGETTO M. R; SILVA M. G; PARADA C. M. G. L. Prevalência de doenças sexualmente transmissíveis em mulheres profissionais do sexo, em um município do interior paulista, Brasil. Rev. Latino-Am. Enfermagem, v. 19, n. 3, maio/jun, 201.

BARROS S. M. O. Enfermagem Obstétrica e Ginecológica guia para a prática assistencial. 2. ed. Editora Roca, 2009.

BELLANGER, A. P. et al. Two Unusual Occurrences of Trichomoniasis: Rapid Species Identification by PCR. Journal of clinical microbiology, v. 46, n. 9, p. 3159- 316I, 2008.

DE CARLI, G. A. et al. Parasitologia Humana. II. ed. Editora Atheneu, 2005.

DU-SARKODIE, Y. et al. Comparison of latex agglutination, wet preparation, and culture for the detection of Trichomonas vaginalis. Sex Transm Infect, v. 8o, p. 201-203, 2004.

BRASIL. Ministério da Saúde. Secretaria de Vigilância em Saúde. Programa Nacional de DST e AIDS. Manual de Controle das Doenças Sexualmente Transmissíveis - DST. $4^{\underline{a}}$ Edição- 2006.

BRASIL. Ministério da Saúde. Secretaria de Atenção à Saúde. Departamento de Ações Programáticas Estratégicas. Política nacional de atenção integral à saúde da mulher: princípios e diretrizes. Editora do Ministério da Saúde, 2007. 
BRASIL. Resolução COFEN № 38I/2oII. Normatiza a execução, pelo Enfermeiro, da coleta de material para colpocitologia oncótica pelo método de Papanicolaou. Disponível em: <http://www.cofen.gov.br/resoluo-cofen-n-38ı2oII_7447.html>

BRASIL. Ministério da Saúde (MS). Política Nacional de Atenção Integral à Saúde do Homem. Plano de Ação Nacional (2009-201I). Brasília: Ministério da Saúde, 2009.

BRASIL. Ministério da Saúde. Secretaria de Vigilância em Saúde. Portaria № 1.459, de 24 de junho de 201r. Rede Cegonha. Disponível em:

〈http://bvsms.saude.gov.br/bvs/folder/rede_cegonha.pdf〉

FALSETTI, D. et al. Condom use, pregnancy, and STDs in adolescent females with and without type I diabetes. Diabetes Educ, v. 29, n. I, p. I35-I43, 2003.

FICHOROVA R. N. Impact of T. Vaginalis Infection on Innate Immune Responses and Reproductive Outcome. J Reprod Immunol, v. 83, n. I-2, p. I85-189, 2009.

FORD, L. J; BROWNING, C. R. Neighborhood Social Disorganization and the Acquisition of Trichomoniasis Among Young Adults in the United States. American Journal of Public Health, v.IoI, n. 9, 2011.

GOODMAN R. P. et al. Trichomonasvirus: a new genus of protozoan viruses in the family Totiviridae. Arch Virol, v. I56, n. I, p. I71-179, 201 .

HOLLOWAY, D. Nursing considerations in patients with vaginitis. Br J Nurs, v.19, n. I6, p. 1040-1046, 2010.

JAIN, A. Novel Trichomonacidal Spermicides. Antimicrobial agents and chemotherapy, v. 55, n. 9, p. 4343-4351, 2011.

LEON R. S. et al. Trichomonas vaginalis Infection and Associated Risk Factors in a SociallyMarginalized Female Population in Coastal Peru. Infectious diseases in obstetrics and gynecology, v. 10, 2009.

LEWIN, L. C. Sexually transmitted infections in preadolescent children. J Pediatr Health Care, v. 2I, n. 3, p. 153-6I, 2007.

LOPES, J. B. et al. Características da população feminina notificada por doenças sexualmente transmissíveis no município de Araraquara. Rev Inst Ciênc Saúde, v. 26, n. 4, p. 409-417, 2008.

LOWE, N. K; RYAN-WENGER, N. A. Military women's risk factors for and symptoms of genitourinary infections during deployment. Mil Med, v.168, n.7, 2003.

MACIEL, G. P; TASCA, T.; DE CARLI, G. A. Aspectos clínicos, patogênese e diagnóstico de Trichomonas vaginalis. J Bras Patol Med Lab, Rio de Janeiro, v. 40, n. 3, p. 152-16o, 2004.

MARION, L. N. The Well Woman Program: a community-based randomized trial to 
prevent sexually transmitted infections in low-income African American women. Res Nurs Health, v. 32, n. 3, p. 274-285, 2009.

MASHBURN, J. Etiology, diagnosis, and management of vaginitis. Midwifery Womens Health, v. 5, p. 423-430, 2006.

MEHTA, S. D. Adult Male Circumcision Does Not Reduce Risk of Incident Neisseria gonorrhoeae, Chlamydia trachomatis, and Trichomonas vaginalis: Results from a Randomized Controlled Trial in Kenya. J Infect Dis, v. 200, 3, p. 370-378, 2009.

MENSCH, B. S. et al. Sexual Behavior and STI/HIV Status Among Adolescents in Rural Malawi: An Evaluation of the Effect of Interview Mode on Reporting. Stud Fam Plann, v. 39, v. 4 , p. 321-334, 2008.

MONTENEGRO, C.A.B.; REZENDE, J. Obstetrícia Fundamental. ir.ed. Editora Guanabara Koogan, 2008

MUNDODI, V. et al. Silencing the ap65 gene reduces adherence to vaginal epithelial cells by Trichomonas vaginalis. Mol Microbiol, v. 53, n. 4, 2004.

ORGANIZAÇÃO MUNDIAL DE SAÚDE. Prevalence and incidence of selected sexually transmitted infections. Chlamydia trachomatis, Neisseria gonorrhoeae, syphilis and Trichomonas vaginalis. Methods and results used by WHO to generate 2005 estimates 2011. Acesso em: http://www.who.int/en/

POMPEO D. A; ROSSI L. A; GALVÃO C. M. Revisão integrativa: etapa inicial do processo de validação de diagnóstico de enfermagem. Acta Paul Enferm, v. 22, n. 4, p. 434-438, 2009.

RYAN-WENGER, N. A. Accuracy of vaginal symptom self-diagnosis algorithms for deployed military women. Nurs Res, v. 59, n. I, p. 2-10, 2010.

SIQUEIRA, L. F.G. et al. Parasitologia humana e seus fundamentos gerais. 2. ed. Editora Atheneu, 2008.

SOUZA, R. P. et al. Simultaneous Detection of Seven Sexually Transmitted Agents in Human Immunodeficiency Virus-Infected Brazilian Women by Multiplex Polymerase Chain Reaction. Am J Trop Med Hyg, v. 89, n. 6, p. II99-I202, 2013.

SUMMERS, A. Identifying non-viral gynaecological conditions. Emerg Nurse, v. 18, n. 9, p. 26-30, 2011.

SCHWEBKE J. R; BURGESS D. Trichomoniasis. Clinical microbiology reviews, p. 794803, 2004 .

TOBIAN A. A. R; GRAY R. H; QUINN T. C. Male Circumcision for the Prevention of Acquisition and Transmission of Sexually Transmitted Infections: The Case for Neonatal 
Circumcision. Arch Pediatr Adolesc Med, v. 164, n. I, p. 78-84, 2010.

WILEY, D. J. et al. Behavioral and sociodemographic risk factors for serological and DNA evidence of HPV6 